Analitika: Jurnal Magister Psikologi UMA, Vol. 11 (2) Desember (2019)

ISSN: 2085-6601 (Print), ISSN: 2502-4590 (Online)

DOI: http://dx.doi.org/analitika.v11i1.2799

\title{
ANALITIKA
}

Jurnal Magister Psikologi UMA

Available online http://ojs.uma.ac.id/index.php/analitika

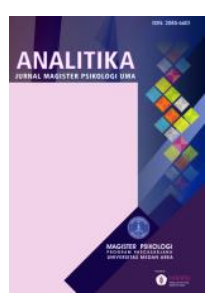

\section{Psikoedukasi Parenting untuk Meningkatkan Pengetahuan Ibu dalam Mengoptimalkan 1000 Hari Pertama Kehidupan}

\section{Psychoeducation of Parenting to Increase Maternal Knowledge in Optimizing The First 1000 Days of Life}

\author{
Christy Ruth Titiari Nainggolan*1) \& Hamidah $^{2)}$ \\ 1)2) Bidang Studi Psikologi Klinis, Program Studi Magister Psikologi Profesi, \\ Fakultas Psikologi, Universitas Airlangga, Indonesia
}

Diterima: 10 Agustus 2019, disetujui: 16 Desember 2019, dipublish: 30 Desember 2019

*Corresponding author: E-mail: christy.nainggolann@gmail.com

\begin{abstract}
Abstrak
Gerakan 1000 Hari Pertama Kehidupan (1000 HPK) merupakan program pemerintah Indonesia yang dibuat dalam rangka mempercepat perbaikan gizi agar tumbuh kembang anak lebih optimal. Puskesmas J di Surabaya telah melaksanakan program ini melalui Posyandu Balita D. Namun, pelaksanaannya belum disertai dengan psikoedukasi sehingga ibu kurang mendapat infomasi lengkap terkait pentingnya program 1000 HPK (ASI Eksklusif, imunisasi, dan gizi) dalam kehidupan anak. Salah satu faktor yang dapat mengoptimalkan program tersebut adalah pengetahuan ibu tentang parenting. Penelitian bertujuan untuk mengetahui perbedaan pengetahuan ibu dalam mengoptimalkan periode 1000 HPK sesudah dilakukan psikoedukasi parenting di Posyandu Balita D. Responden penelitian berjumlah 23 ibu balita dipilih melalui teknik purposive sampling. Desain penelitian menggunakan one group pretest-posttest. Pengumpulan data menggunakan kuesioner disusun oleh peneliti berdasarkan materi psikoedukasi. Hasil analisis data dengan Paired Sample T-Test menunjukkan signifikansi sebesar $0.000(\mathrm{p}<0.05)$ yang berarti ada peningkatan pengetahuan ibu dalam mengoptimalkan 1000 HPK setelah dilakukan psikoedukasi parenting di Posyandu Balita D. Hasil penelitian ini diharapkan menjadi rekomendasi bagi Puskesmas J agar menerapkan psikoedukasi parenting di seluruh Posyandu Balita dalam wilayah kerjanya guna mendukung 1000 HPK.
\end{abstract}

Kata Kunci: Psikoedukasi, parenting, pengetahuan ibu, 1000 hari pertama kehidupan

\begin{abstract}
The First 1000 Days of Life Movement (1000 HPK) is an Indonesian government program designed to accelerate the nutrition improvement that leads to optimal children's growth and development. Puskesmas J in Surabaya has implemented this program through Posyandu Balita D. However, the implementation of this program has not been followed by a psychoeducation session that causes mothers do not receive a complete information about the importance of 1000 HPK program (breastfeeding, immunization, and nutrition) in their children's life. One of the most important factors in optimizing the implementation of this program is the maternal knowledge of parenting. The purpose of this study is to determine the difference about the maternal knowledge in optimizing the 1000 HPK program after psychoeducation session in Posyandu Balita D. Respondents of this study were 23 mothers of toddler who were selected based on purposive sampling technique. The study design used one group pretest-posttest. The data were collected by using a questionnaire compiled by researcher based on psychoeducation materials. The result of data analysis using Paired Sample T-Test showed a significance value of $0.000(p<0.05)$ that means there was an increasing in the maternal knowledge in optimizing 1000 HPK after psychoeducation of parenting in Posyandu Balita $D$. The result is expected to be a recommendation for Puskesmas J to implement the psychoeducation of parenting in all of Posyandu Balita in their working area to support 1000 HPK.
\end{abstract}

Keywords: Psychoeducation, parenting, maternal knowledge, 1000 first days of life

How to Cite: Nainggolan, C.R.T. \& Hamidah. (2019), Psikoedukasi Parenting untuk Meningkatkan Pengetahuan Ibu dalam Mengoptimalkan 1000 Hari Pertama Kehidupan, Analitika: Jurnal Magister Psikologi UMA, 11 (2): 88 - 97 


\section{PENDAHULUAN}

Periode 1000 Hari Pertama Kehidupan (1000 HPK) adalah masa tumbuh kembang anak yang dimulai sejak dalam kandungan sampai berusia dua tahun. Periode ini disebut Golden Age karena terjadi pertumbuhan otak sangat pesat yang dapat menentukan kualias hidup anak di masa depan. Aspek penting dalam periode 1000 HPK adalah pemenuhan kebutuhan gizi anak (Kementerian Kesehatan RI, 2014).

Dampak buruk apabila gizi anak tidak terpenuhi selama periode 1000 HPK seperti terganggu pertumbuhan fisik, perkembangan otak, dan imunitas yang rendah (Kementerian Koordinator Ekonomi \& Kesejahteraan RI, 2013). Dampak jangka panjang kekurangan gizi akan berpengaruh terhadap prestasi belajar rendah dan kurang produktif anak sebagai generasi penerus bangsa (Dewey \& Begum, 2011).

Kekurangan gizi menjadi masalah kesehatan utama anak di dunia, termasuk Indonesia (Zulkarnain, 2012). Hasil Riset Kesehatan Dasar 2018 menunjukkan bahwa Indonesia memiliki masalah gizi anak dengan persentase Bayi Berat Lahir Rendah (BBLR) 6.2\%, balita kurang gizi dan gizi buruk $17.7 \%$, balita kurus $10.2 \%$, dan balita pendek (stunting) 30.8\% (Kementerian Kesehatan RI, 2018).

Pada tahun 2010, PBB membuat gerakan Scalling Up Nutrition (SUN Movement) sebagai respon masalah gizi anak, seperti stunting. Indonesia menjadi negara kelima balita stunting tertinggi di dunia berjumlah \pm 7.5 juta anak (UNICEF, 2013). Indonesia ikut bergabung dalam SUN Movement tahun 2011 dengan membuat program "Gerakan 1000 HPK" yang bertujuan mempercepat perbaikan gizi anak (Pemerintah Indonesia, 2013).

Provinsi Jawa Timur memiliki persentase balita kurang gizi dan gizi buruk $16.8 \%$, balita kurus $11.4 \%$, dan balita stunting 32.81\% (Kementerian Kesehatan RI, 2018). Oleh karena itu, Pemerintah Kota Surabaya (2016) membuat rencana program peningkatan kesehatan balita sebagai bagian program Gerakan 1000 HPK seperti ASI Eksklusif, imunisasi lanjutan, dan gizi. Program ini ditujukan kepada Puskesmas sebagai layanan kesehatan tingkat pertama (Dinas Kesehatan Kota Surabaya, 2017).

Puskesmas J adalah salah satu puskesmas di Surabaya yang berperan dalam program Gerakan 1000 HPK melalui Posyandu Balita D. Hasil wawancara dengan penanggung jawab Posyandu Balita D diperoleh informasi terkait kondisi ibu sebagai pengasuh utama masih kurang peduli dengan kebutuhan gizi dan kesehatan balita-nya seperti tidak memberikan ASI Eksklusif, menolak imunisasi lanjutan, dan tidak memenuhi kebutuhan gizi balita.

Susu formula dinilai lebih praktis menjadi salah satu faktor rendahnya ASI Eksklusif (Pebriana \& Sulistyoningtyas, 2015). Kementerian Kesehatan RI mencatat angka ASI Eksklusif Indonesia tahun 2017 hanya \pm 35\% (Juniman, 2018). Padahal penelitian menemukan bahwa ASI berdampak positif pada kemampuan balita (kognitif, emosi, dan sosial) serta meningkatkan kelekatan antara ibu dan balita (Tasnim, 2014; Gibbs \& Forste, 2014; Lawrence, 2017).

Kondisi lain ditemukan masih ada ibu yang menolak imunisasi lanjutan 
(Pentavalen Booster dan MR Booster) dengan alasan tidak memiliki waktu membawa balita imunisasi, tidak mau lagi menangani efek setelah imunisasi, dan berpikir imunisasi dasar sudah cukup. Hasil wawancara juga diketahui masih terdapat ibu yang tidak mengenalkan makanan sesuai usia balita dan membiarkan balita mengonsumsi makanan kurang bergizi.

Masalah gizi balita tidak hanya disebabkan faktor ekonomi, namun juga karena faktor kurangnya pengetahuan orangtua tentang gizi balita. Beberapa penelitian menemukan ada hubungan yang signifikan antara pengetahuan orangtua dan praktik pemberian makan balita dengan status gizi balita (Saaka, 2014; Morowatisharifabad, Khankolabi, Khosravi, Fallahzade, \& Abargouei, 2017; Maesarah, Pakaya, \& Djafar, 2018).

Beberapa gambaran kondisi ibu balita tersebut berkaitan dengan pola asuh (parenting). Menurut Hurlock (1999), pola asuh adalah perlakuan sehari-hari orangtua yang membentuk anak berperilaku dan bersosialisasi. Pola asuh (parenting) akan mendidik anak untuk tumbuh menjadi individu dewasa secara sosial (Santrock, 2012). Salah satu faktor yang berpengaruh pada periode 1000 HPK adalah pola asuh (parenting) (UNICEF, 2013).

Tumbuh kembang selama periode 1000 HPK tidak hanya fokus pada aspek fisik, namun juga memperhatikan aspek psikososial seperti pola asuh (parenting). Nurunniyah \& Sugesti (2016) menemukan ada hubungan signfikan antara pola asuh dengan ASI Eksklusif. Status gizi berkaitan dengan orangtua, balita mengonsumsi makanan sehat atau tidak bergantung pola asuh (Hoffman, Marx, Burmeister, \& Eizenman, 2016).

Hasil observasi di Posyandu Balita D menemukan ada ibu yang melakukan kekerasan fisik (cubit, pukul) dan verbal (marah, teriak, kata kasar) kepada balita, ibu lebih fokus dengan handphone, sementara balita dibiarkan bermain sendiri. Kader Balita menyampaikan bahwa banyak ibu kurang memanfaatkan waktu bersama balita, seperti bermain. Padahal aktivitas bermain menjadi stimulasi baik untuk balita (Rao, Sun, Wong, Weekes, Ip, Shaeffer, Young, Bray, Chen, \& Lee, 2014).

Anak memiliki tiga kebutuhan dasar yakni Asuh (fisik), Asih (kasih sayang), dan Asah (stimulasi). Kebutuhan dasar tersebut sebaiknya dipenuhi oleh orangtua selama periode $1000 \mathrm{HPK}$ dengan pola asuh yang tepat agar tumbuh kembang balita lebih optimal (Kementerian Kesehatan RI, 2014). Stimulasi yang tepat ditambah gizi lengkap akan meningkatkan kemampuan kognitif, emosi, dan sosial anak (Novita, 2013; Elmanora, Hastuti, \& Muflikhati, 2017; Biedinger \& Biedinger, 2011).

Hasil wawancara dengan Kader Balita diperoleh informasi bahwa Puskesmas J telah melakukan edukasi gizi dan kesehatan fisik balita kepada ibu di Posyandu Balita D, namun belum secara mendalam khususnya terkait pentingnya periode 1000 HPK bagi tumbuh kembang anak. Puskesmas J juga belum pernah memberikan psikoedukasi parenting kepada seluruh ibu di Posyandu Balita wilayah kerjanya.

Berdasarkan kondisi tersebut, maka dapat diidentifikasi bahwa ibu di Posyandu Balita D kurang mendapat 
informasi mendalam terkait pentingnya periode 1000 HPK dan pola asuh yang tepat agar tumbuh kembang balita lebih optimal. Oleh karena itu, ibu balita perlu mendapat informasi lengkap terkait parenting dalam periode $1000 \mathrm{HPK}$.

Beberapa penelitian sebelumnya terkait program 1000 HPK di Indonesia masih berfokus pada aspek fisik yakni edukasi gizi dan kesehatan fisik calon pengantin dan ibu hamil (masa prenatal) (Muthi'ah, 2017; Pratama, Riyanti, \& Cahyo, 2017; Naim, Juniarti, \& Yamin, 2017). Berbeda dengan penelitian ini yang berfokus pada aspek psikososial yakni psikoedukasi parenting bagi ibu terhadap balita (masa post-natal).

Berdasarkan fenomena tersebut, penelitian bertujuan untuk mengetahui perbedaan pengetahuan ibu dalam mengoptimalkan periode 1000 HPK setelah psikoedukasi parenting di Posyandu Balita D. Hipotesis penelitian yang diajukan yakni adanya peningkatan pengetahuan ibu dalam mengoptimalkan periode 1000 HPK setelah psikoedukasi parenting di Posyandu Balita D.

\section{METODE PENELITIAN}

Penelitian ini menggunakan tipe penelitian kuantitatif dengan desain penelitian one group pretest-posttest design. Karakteristik responden penelitian adalah ibu yang memiliki balita dan terdaftar sebagai anggota di Posyandu Balita D. Responden penelitian berjumlah 23 orang ibu balita yang dipilih melalui teknik purposive sampling.

Pengumpulan data menggunakan kuesioner yang disusun oleh peneliti berdasarkan materi psikoedukasi parenting yang diberikan yakni Periode
1000 HPK, Tumbuh Kembang Anak, dan Pola Asuh (Parenting). Kuesioner yang diberikan kepada responden telah mendapat professional judgement dari dosen. Kuesioner penelitian berjumlah 10 aitem, dimana responden akan diminta untuk memilih 1 dari 4 jawaban yang paling sesuai. Jawaban benar bernilai 1 dan salah bernilai 0 , sehingga skor tertinggi adalah 10 dan skor terendah adalah 0 .

Analisis data menggunakan Uji Beda Paired Sample T-Test dengan bantuan SPSS Statistics 24 for Windows. Paired Sample T-Test digunakan untuk melihat perbandingan data sebelum psikoedukasi (pretest) dan setelah psikoedukasi (posttest). Hal ini bertujuan untuk melihat perbedaan peningkatan pengetahuan pada responden sebelum dan sesudah pelaksanaan psikoedukasi parenting.

Psikoedukasi parenting dilakukan dalam sekali pertemuan dengan durasi 2 jam 45 menit. Psikoedukasi diberikan dalam bentuk penyampaian materi, pemutaran video parenting, role play, dan leaflet agar responden lebih mudah memahami. Psikoedukasi parenting dilakukan dalam 8 sesi yang tertera pada Tabel 1 berikut :

Tabel 1

Pelaksanaan Psikoedukasi Parenting

\begin{tabular}{clc}
\hline Sesi & \multicolumn{1}{c}{ Kegiatan } & Durasi \\
\hline I & Pembukaan & 10 Menit \\
II & Materi "Periode 1000 HPK" & 25 Menit \\
III & Materi "Tumbuh Kembang" & 25 Menit \\
IV & $\begin{array}{l}\text { Materi "Pola Asuh terhadap } \\
\text { Tumbuh Kembang Anak pada }\end{array}$ & \\
& Tenit \\
& Periode 1000 HPK" \\
V & Pemutaran Video "To Be a & 10 Menit \\
& Good Parent" & \\
VI & Role Play & 15 Menit \\
VII & Diskusi \& Tanya Jawab & 30 Menit \\
VIII & Penutup & 10 Menit \\
\hline
\end{tabular}




\section{HASIL DAN PEMBAHASAN}

Berdasarkan identitas, diperoleh responden penelitian memiliki 1 orang balita (78.2\%) dan 2 orang balita (21.8\%). Sebagian besar responden adalah ibu rumah tangga (82.6\%) dan wiraswasta (17.4\%). Ibu rumah tangga adalah sosok wanita yang menghabiskan waktu mengurus pekerjaan rumah dan mengasuh anak. Responden sebagai ibu rumah tangga seharusnya mampu mengasuh lebih baik karena memiliki waktu lebih banyak bersama anak.

Pudjiwati (1997) menemukan sebaliknya, ibu rumah tangga lebih fokus mengurus pekerjaan rumah dibanding mengasuh anak. Hal ini didukung wawancara dengan responden yang menyampaikan bahwa waktu dan tenaga banyak digunakan untuk mengerjakan pekerjaan rumah sehingga mudah lelah. Kondisi tersebut yang membuat responden memiliki sedikit kesempatan bersama dan bermain dengan balita.

Tingkat pendidikan responden adalah SMA (43.47\%), D3 (30.43\%), SMP (17.40\%), dan SD (8.70\%). Tingkat pendidikan berhubungan dengan pengetahuan. Apabila pengetahuan orangtua terbatas maka berdampak pada balita kurang atau tidak menerima stimulasi. Semakin tinggi pendidikan orangtua, maka pengetahuan tentang tumbuh kembang anak semakin baik, sehingga dapat memberikan gizi dan stimulasi yang tepat bagi anak (fisik, emosi, dan sosial) (Evans, Myers, \& Ilfeld, 2000; Vollmer, Bommer, Krishna, Harttgen, \& Subramanian, 2017).

Data pretest setelah dianalisis diperoleh nilai terendah sebesar 4 (17.40\%) dan nilai tertinggi sebesar 7
(13.04\%) dengan nilai mean diperoleh sebesar 5.17. Setelah posttest, diperoleh nilai terendah sebesar 8 (4.34\%) dan tertinggi sebesar 10 (17.40\%) dengan nilai mean meningkat sebesar 9.13. Berdasarkan data tersebut, disimpulkan bahwa nilai pengetahuan responden (100\%) meningkat setelah psikoedukasi.

Sebelum dilakukan analisis uji beda Paired Sample T-Test, terlebih dahulu dilakukan uji normalitas pada data penelitian. Adapun hasil uji normalitas tertera pada Tabel 2 berikut :

Tabel 2

Hasil Uji Normalitas

\begin{tabular}{cccc}
\hline Data & $\begin{array}{c}\text { Skewness } \\
\text { Statistic }\end{array}$ & $\begin{array}{c}\text { Kurtosis } \\
\text { Statistic }\end{array}$ & Ket. \\
\hline $\begin{array}{c}\text { Nilai } \\
\text { Pretest } \\
\text { Nilai }\end{array}$ & 0.03 & -0.76 & Normal \\
Posttest & 0.06 & 1.89 & Normal \\
\hline
\end{tabular}

Uji normalitas dapat dilihat dari nilai skewness dan kurtosis. Syarat data tergolong normal jika memiliki nilai skewness dalam rentang - 1 sampai 1 dan nilai kurtosis dalam rentang -2 sampai 2 . Apabila melihat data nilai pretest dan posttest pada Tabel 2, maka disimpulkan bahwa nilai skewness dan kurtosis bermakna data berdistribusi normal.

Setelah diperoleh data penelitian terdistribusi normal, maka selanjutnya dilakukan analisis statistik Uji Beda Paired Sample T-Test.

Tabel 3

Uji Beda Paired Sample T-Test Pretest dan Posttest Psikoedukasi Parenting

\begin{tabular}{ccccc}
\hline Data & Mean & $\begin{array}{c}\text { Std. } \\
\text { Dev }\end{array}$ & T & $\begin{array}{c}\text { Sig. (2- } \\
\text { tailed) }\end{array}$ \\
\hline $\begin{array}{l}\text { Pretest- } \\
\text { Posttest }\end{array}$ & -3.96 & 1.063 & -16.67 & 0.000 \\
\hline
\end{tabular}

Berdasarkan hasil analisis Uji Beda pada Tabel 3, diperoleh nilai signifikansi sebesar $0.000(p<0.05)$ bermakna bahwa 
terdapat perbedaan yang signifikan antara nilai pretest dan posttest. Oleh karena itu hipotesis dalam penelitian ini diterima, sehingga dapat disimpulkan bahwa adanya peningkatan pengetahuan ibu dalam mengoptimalkan 1000 HPK setelah pelaksanaan psikoedukasi parenting di Posyandu Balita D.

Psikoedukasi parenting dibuat berdasarkan analisis kebutuhan Posyandu Balita D yakni ibu balita sebagai responden penelitian belum mendapat informasi lengkap terkait pentingnya program 1000 HPK. Puskesmas J juga belum pernah melakukan psikoedukasi parenting di Posyandu Balita D sehingga responden belum pernah mendapat pengetahuan tentang parenting. Hal tersebut sangat penting dilakukan karena parenting menjadi salah satu faktor yang berpengaruh dalam mengoptimalkan tumbuh kembang anak selama 1000 HPK (UNICEF, 2013).

$$
\text { HIMPSI (2010) mendefinisikan }
$$
bahwa psikoedukasi adalah kegiatan untuk meningkatkan pemahaman individu, kelompok, dan komunitas. Pada penelitian ini, responden memperoleh berbagai pengetahuan baru mengenai pentingnya periode 1000 HPK bagi kehidupan anak, tumbuh kembang anak, dan pola asuh. Ketiga informasi tersebut berperan penting dalam proses tumbuh kembang anak pada periode 1000 HPK. Pemahaman responden juga dibantu dengan role play dan pemutaran video singkat tentang parenting.

Hasil penelitian ini menunjukkan bahwa psikoedukasi parenting dapat meningkatkan pengetahuan responden dalam mengoptimalkan periode 1000
HPK. Responden mendapat informasi baru tentang parenting agar dapat mengembangkan keterampilan dalam mengasuh anak secara tepat selama periode 1000 HPK. Hal ini sesuai dengan Walsh (2010), psikoedukasi adalah penyampaian informasi dan membantu pengembangan keterampilan coping individu dan kelompok menghadapi tantangan atau masalah hidup.

Hasil penelitian ini didukung oleh beberapa penelitian sebelumnya terkait psikoedukasi yang dapat meningkatkan pengetahuan kelompok atau komunitas. Nugroho \& Adiyanti (2011) menemukan bahwa psikoedukasi efektif dapat meningkatkan pengetahuan guru dan keterampilan menangani perilaku bullying. Hadidi (2014) juga menemukan bahwa psikoedukasi berpengaruh signifikan meningkatkan pengetahuan pada pasien hipertensi dan katarak (Siswoyo, 2015).

Pengetahuan baru responden mengenai parenting dapat membantu mengoptimalkan tumbuh kembang anak selama periode 1000 HPK. Oleh karena itu, diharapkan pengetahuan baru tersebut dapat membantu mengubah pola pikir dan perilaku pengasuhan ibu kepada balita selama ini. Pengetahuan tentang tumbuh kembang balita tersebut dapat mendorong ibu untuk memberikan pola asuh yang tepat bagi anaknya agar tumbuh kembang lebih optimal.

Hal ini sejalan dengan penelitian dilakukan oleh Taufiqurrahman (2013) yang menemukan ada hubungan signifikan antara pengetahuan ibu dengan pola asuh balita. September, Rich, \& Roman (2017) juga menemukan ada hubungan signifikan antara pengetahuan 
tentang perkembangan anak terhadap pola asuh orangtua.

Responden tidak hanya meningkat pengetahuan parenting namun juga pengetahuan tentang perkembangan anak sehingga mendapat pengetahuan lengkap dalam mengoptimalkan tumbuh kembang anak. Sanders \& Morawska (2014) mengatakan apabila orangtua memiliki banyak pengetahuan tentang perkembangan anak, maka keterampilan pengasuhan menjadi lebih baik. Namun, apabila pengetahuan orangtua rendah maka berkorelasi dengan perkembangan anak kurang optimal (Yue, Whu, Shi, Luo, Wang, Kenny, \& Rozelle, 2017).

Psikoedukasi parenting ini dapat mendukung program pemerintah Gerakan 1000 HPK. Parenting menjadi faktor dalam mengoptimalkan tumbuh kembang anak selama periode 1000 HPK (UNICEF, 2013). Hal ini sejalan dengan Rao dkk (2014), program parenting didesain untuk orangtua yang memiliki anak di bawah umur dua tahun yang berfokus pada pemenuhan gizi anak, pengasuhan, dan stimulasi. Program parenting menjadi penguat faktor protektif dan meminimalisir faktor resiko (gangguan perkembangan anak) (Walker, Wachs, McGregor, \& Black, 2011).

Selama psikoedukasi berlangsung, banyak responden terlihat kooperatif dan antusias. Responden aktif terlibat dalam role play, diskusi, dan tanya jawab. Berdasarkan hasil analisis kualitatif melalui wawancara dengan beberapa responden, psikoedukasi parenting ini mendorong responden untuk melakukan refleksi diri sebagai orangtua terhadap pengasuhan yang diterapkan selama ini. Banyak responden berbagi pengalaman terkait pola asuh kurang tepat, seperti marah, memukul, berteriak, berkata kasar, mengabaikan, tidak memberi ASI Eksklusif, dan membiasakan balita dengan makanan kurang bergizi.

Pola asuh sangat penting selama proses tumbuh kembang balita untuk meminimalisir terjadinya masalah atau gangguan perkembangan anak. Regalado (Santrock, 2012) mengatakan bahwa kekerasan fisik dan verbal dapat menurunkan kepercayaan diri anak dan menimbulkan masalah atau gangguan perkembangan anak. Sebaliknya, apabila anak mendapat dukungan, kehangatan, dan kasih sayang membuat anak lebih percaya diri dan disayangi, sehingga tumbuh kembang anak menjadi lebih baik kedepan (Schunk, Castro, Vasconcelos, Dultra, \& Goldani, 2013).

Responden semakin memahami bahwa aspek psikososial (perhatian, kasih sayang, dan stimulasi) sangat dibutuhkan oleh balita dalam proses tumbuh kembangnya agar lebih optimal, selain pemenuhan aspek fisik. Oleh karena itu, banyak responden memiliki keinginan untuk mengubah pola pikir dan menerapkan praktik pengasuhan yang lebih baik untuk balita. Responden menjadi lebih sadar bahwa pengasuhan orangtua berpengaruh terhadap tumbuh kembang balita agar lebih optimal.

Pola asuh yang tepat dibutuhkan untuk tumbuh kembang anak lebih optimal. Hal tersebut dikaitkan dengan pengetahuan orangtua terhadap pola asuh (Soetjiningsih, 2012). Tidak hanya terbatas dengan psikoedukasi parenting, responden juga dapat mencari informasi pola asuh dan perkembangan balita melalui media cetak, elektronik, internet, 
dan konsultasi dengan ahli (Kurniawati \& Mardiyanti, 2014; Rehman, Munir, \& Kazmi, 2016). Saat pemenuhan gizi, stimulasi, dan pola asuh yang tepat terpenuhi maka tumbuh kembang balita dalam periode 1000 HPK lebih optimal.

Sebulan setelah pelaksanaan psikoedukasi, peneliti melakukan follow up kepada responden dengan membuat kegiatan "Parenting Corner". Peneliti meminta responden untuk mengingat kembali materi psikoedukasi, role play tentang pengasuhan baru yang sudah diterapkan, dan tanya jawab. Kegiatan seperti ini diharapkan dapat dilakukan setiap bulan oleh Kader Balita dan ibu balita di Posyandu Balita D saat kegiatan penimbangan berkala sebagai wadah berbagi informasi dan diskusi terkait parenting dan tumbuh kembang anak.

Saran pengembangan terkait psikoedukasi parenting kedepan yakni : (1) Bagi Responden, agar menerapkan pola asuh yang lebih baik kepada balita tidak sebatas pada 1000 HPK namun untuk kedepan, dan bila merencanakan kehamilan selanjutnya agar menerapkan pengetahuan yang diperoleh sehingga tumbuh kembang anak lebih optimal sejak di kandungan (2) Bagi Keluarga, ayah diharapkan ikut berperan serta dalam pola asuh untuk tumbuh kembang anak lebih optimal (3) Bagi Puskesmas J, menerapkan psikoedukasi parenting di Posyandu Balita wilayah kerjanya guna mendukung program 1000 HPK dan melatih keterampilan para Kader Balita tentang parenting yang dapat dibagikan kepada seluruh ibu yang berada dalam naungan Posyandu Balita (4) Bagi peneliti selanjutnya, hasil diskusi dalam psikoedukasi seperti keterlibatan peran ayah dalam mengasuh anak, stres pengasuhan, dan deteksi dini tumbuh kembang anak dapat dijadikan need of assessment untuk penelitian selanjutnya.

\section{SIMPULAN}

Penelitian ini menemukan hasil bahwa adanya peningkatan pengetahuan ibu dalam mengoptimalkan periode 1000 HPK setelah pelaksanaan psikoedukasi parenting di Posyandu Balita D. Oleh karena itu, psikoedukasi parenting dapat menjadi rekomendasi bagi Puskesmas J untuk menerapkan di seluruh Posyandu Balita wilayah kerjanya guna mendukung program pemerintah yakni Gerakan 1000 HPK.

\section{UCAPAN TERIMA KASIH}

Terimakasih kepada Badan Narkotika Nasional Republik Indonesia (BNN RI) yang telah memberi dana dalam mendukung penyelesaian penelitian ini.

\section{DAFTAR PUSTAKA}

Anderson, L.S. (2008). Predictors of parenting stress in a diverse sample of parents of early adolescents in high-risk communities. Nursing Research, 57(5), 340-350.

Biedinger, N., \& Biedinger, N. (2011). The Influence of Education and Home Environment on the Cognitive Outcomes of Preschool Children in Germany. Child Development Research. 1-10.

Dewey, K.G., \& Begum K. (2011). Long-term Consequences of Stunting In Early Life. Blackwell Publishing Ltd Maternal and Child Nutrition. 7 (3): 5-18.

Dinas Kesehatan Kota Surabaya. (2017). Profil Kesehatan Tahun 2016. Surabaya: Dinas Kesehatan Kota Surabaya.

Elmanora, Hastuti, D., \& Muflikhati, I. (2017). Lingkungan Keluarga sebagai Sumber Stimulasi untuk Perkembangan Kognitif Anak Usia Prasekolah. Jur. Ilm. Kel. E Kons. 10 (2): 143-156. 
Evans, J.L., Myers, R.G., \& Ilfeld, E.M. (2000). Early Childhood Counts: A Programming Guide on Early Childhood Care for Development. New York: The World Bank.

Gibbs, B.G., \& Forste, R. (2014). Breastfeeding, Parenting, and Early Cognitive Development. The Journal of Pediatrics. 164(3): 487-493. doi:10.1016/j.jpeds.2013.10.015

Hadidi, K. (2014). Pengaruh Psikoedukasi terhadap Pengetahuan, Koping, Kepatuhan, dan Tekanan Darah pada Lansia dengan Hipertensi Menggunakan Pendekatan Model Teori Adaptasi Roy. Tesis. Universitas Airlangga, Surabaya.

HIMPSI. (2010). Kode Etik Psikologi Indonesia. Jakarta: Pengurus Pusat Himpunan Psikologi Indonesia.

Hoffmann, D.A., Marx J.M., Burmeister, A.K., \& Eizenman, D.R.M. (2016). Influence of Maternal Feeding Goals and Practices on Children's Eating Behaviors. Appetite. 107.

Hurlock, E.B. (1999). Psikologi Perkembangan: Suatu Pendekatan Sepanjang Rentang Kehidupan. Edisi Kelima. Jakarta: Erlangga.

Juniman, P.T. (2018). Angka Pemberian ASI Eksklusif di Indonesia Masih Rendah. Diunduh di https://www.cnnindonesia.com/gayahidup/20180820165738-255-323681/angkapemberian-asi-eksklusif-di-indonesiamasih-rendah tanggal 22 Juli 2019.

Kementerian Kesehatan RI. (2014). Keluarga Sehat Idamanku, Kota Sehat Kotaku.

Kementerian Kesehatan RI. (2018). Hasil Utama Riskesdas 2018.

Kementerian Koordinator Bidang Ekonomi dan Kesejahteraan Rakyat RI. (2013). Kerangka Kebijakan Gerakan 1000 Hari Pertama Kehidupan.

Kurniawati, L.D., \& Mardiyanti, I. (2014). Pola Asuh Orangtua Mempengaruhi Perkembangan Balita di Posyandu Arjuna IV Pos 3 Kelurahan Kemayoran Kecamatan Krembangan Surabaya. Jurnal Ilmu Kesehatan. 7 (12): 9-16.

Lawrence, M.A. (2017). Supporting Breastfeeding/Early Childhood Social and Emotion Development. CEECD/SKC-ECD Breastfeeding. 1-5.

Maesarah, Djafar L., \& Pakaya, F. (2018). Hubungan Perilaku Orangtua dengan Status Gizi Balita di Desa Bulalo Kab. Gorontalo Utara. Gorontalo Journal of Public Health. 1 (1): 39-45.
Morowatisharifabad, M.A., Khankolabi, M., Khosravi, H.M., Fallahzade, H., Abargouei, A.S. (2017). Parenting Style, Parental Feeding Practices and Children's Nutritional Status in Authoritative Parenting Style Model: A Structural Equation Modelling. Iran Red Crescent Med J. 19 (3): 1-7. doi: 10.5812/ircmj.41401.

Muthi'ah, A. (2017). Efikasi Pemberian Edukasi Terkait 1000 Hari Pertama Kehidupan terhadap Pengetahuan dan Sikap Calon Pengantin Wanita. Skripsi. Institut Pertanian Bogor.

Naim, R., Juniarti, N., \& Yamin, A. (2017). Pengaruh Edukasi Berbasis Keluarga terhadap Intensi Ibu Hamil untuk Optimalisasi Nutrisi pada 1000 Hari Pertama Kehidupan. Jurnal Keperawatan Padjajaran. 5 (2). 184-196.

Novita, D. (2013). Hubungan Stimulasi Psikososial di Rumah dan Proses Pembelajaran dengan Kecerdasan Majemuk Anak Taman Kanak Kanak di Kecamatan Pamulang Kota Tangerang. Tesis. Institut Pertanian Bogor.

Nugroho, S., \& Adiyanti, M.G. (2011). Program Psikoedukasi untuk Meningkatkan Pengetahuan dan Keterampilan Guru dalam Menangani Bullying. Jurnal Intervensi Psikologi. 2 (1): 25-48.

Nurunniyah, S., \& Sugesti, D.T. (2016). Pengasuhan Berhubungan dengan Keberhasilan Pemberian ASI Eksklusif pada Baduta di Kecamatan Sedayu. Jurnal Gizi dan Dietetik Indonesia. 4 (1): 1-7.

Pebriana, N., \& Sulistyoningtyas, S. (2015). Faktor yang Mempengaruhi Rendahnya Cakupan ASI Eksklusif di Puskesmas Umbulharjo 1 Kota Yogyakarta. Skripsi. Stikes Aisyah Yogyakarta.

Pemerintah Indonesia. (2013). Peraturan Presiden Republik Indonesia Nomor 42 Tahun 2013 tentang Gerakan Nasional Percepatan Perbaikan Gizi.

Pemerintah Kota Surabaya. (2016). Peraturan Daerah Kota Surabaya Nomor 10 Tahun 2016 tentang Rencana Pengembangan Jangka Menengah Kota Surabaya Tahun 2016-2021.

Pratama, A.P., Riyanti, E., \& Cahyo, K. (2017). Pengaruh Edukasi Gerakan 1000 HPK terhadap Perbaikan Pola Makan Ibu Hamil Risti di Wilayah Kerja Puskesmas Kedungmundu Kota Semarang. Jurnal Kesehatan Masyarakat (e-Journal). 5 (5): 926-938. 
Rao, N., Sun. J., Wong, J.M.S, Weekes, B., Ip, P., Shaeffer, S., Young, M., Bray, M., Chen, E., \& Lee, D. (2004). Early Childhood Development and Cognitive Development in Developing Countries: A Rigorous Literature Review. London: Department for International Development.

Rehman, A.U., Munir, F., \& Kazmi, S.F. (2016). Mother's Knowledge about Child Development. Pakistan Pediatric Journal. 40(3): 176-81.

Saaka, M. (2014). Relationship between Mothers' Nutritional Knowledge in Childcare Practices and the Growth of Children Living in Impoverished Rural Communities. J Health Popul Nutr. 32 (2): 237-248.

Sanders, M.R., \& Morawska, A. (2014). Can Changing Parental Knowledge, Dysfunctional Expectations and Attributions, and Emotion Regulation Improve Outcomes for Children?. CEED/SKC-ECD Parenting Skills. 1-9.

Santrock, J.W. (2012). Live Span Development. $13^{\text {th }}$ Edition. University of Texas, Dallas: Mc Graw-Hill.

Schunk, I., Castro, T.G., Vasconcelos, F.A.G., Dutra, C.L.C., Goldani, M.Z. (2013). Excess Weight in PreSchoolers: Prevalence and Associated Factors. J Pediatr (Rio J). 89 (2): 179-88.

September, S.J. Rich, E. \& Roman, N. (2017). Association Betwwen Knowledge of Child Development and Parenting: A Systematic Review. The Open Family Studies Journal. 9. 1-14. doi: 10.2174/1874922401709010001.

Siswoyo. (2015). Pengaruh Psikoedukasi terhadap Pengetahuan, Intensi, dan Sick Role Behavior pada Pasien Katarak dengan Pendekatan Model Theory of Planned Behavior Ajzen. Jurnal Ilmu Keperawatan. 3(2): 198-210.

Soetjiningsih. (2012). Tumbuh Kembang Anak. Buku Kedokteran, EGC: Jakarta.

Tasnim, S. (2014). Effect of Breastfeeding on Child Development: At Birth and Beyond. South East Asia Journal of Public Health. 4 (1): 4-8.

Taufiqurrahman, M. (2013). Hubungan Tingkat Pengetahuan Ibu tentang Gizi dengan Status Gizi Balita di Kecamatan Kalibagor Kabupaten Banyumas. Skripsi. Unsoed, Purwokerto.

UNICEF. (2013). Improving Child Nutrition, the Achievable Imperative for Global Progress.
New York: United Nations Children's Fund.

Vollmer, S., Bommer, C., Khrisna, A., Harttgen, K., Subramanian, SV. (2017). The Association of Parental Education with Childhood Undernutrition in Low-MiddleIncome Countries: Comparing the Role of Paternal and Maternal Education. International Journal of Epidemiology. 46 (1): 312-323. doi: 10.1093/ije/dyw133.

Walker, S.P., Wachs, TD., Mc.Gregor, S.M., Black, M.M., Nelson, C.A., Huffman, S.L. (2011). Inequality in Early Childhood: Risk and Protective Factors for Early Child Development. The Lancet Journal. 378 (9799): 1325-1338.

Yue, A., Wu, M., Shi, Y., Luo, R., Wang, B., Kenny, K., Rozelle, S. (2017). The Relationship between Maternal Parenting Knowledge and Infant Development Outcomes: Evidence from Rural China. Diunduh di https://pdfs.semanticscholar.org/fi54/8d 4 65e23fbf6cegc9aad61dfe633ege32f5a.pdf. tanggal 20 Juli 2019.

Zulkarnain, M.R. (2016). Yuk, Sukseskan Gerakan 1000 HPK. Food for Kid Indonesia. Ed 1. Vol 4. 